\title{
Flood forecast based on numerical weather prediction and distributed runoff model
}

\author{
H. Kardhana, H. Tatesawa \& A. Mano \\ Department of Civil Engineering, Tohoku University, Japan
}

\begin{abstract}
The accuracy of quantitative precipitation forecast from numerical weather prediction (NWP) grows as higher resolutions are achieved by the computation capacity of supercomputers. Various distributed dataset, globally and locally, with better spatial and temporal resolution has been rapidly developed. The objective of this paper is to have a flood forecast model that utilises these great benefits and gives reliable accuracy.

Another asset of a flood forecast model is a conceptual-distributed runoff model; it has been chosen because of its simplicity. Calibration and validation of the model has been met by good agreement for events in 2002 in the case of a $237 \mathrm{~km}^{2}$ operational scale basin. These results are based on input Grid Point Value (GPV) precipitation of Japan radar observation.

Forecasted Precipitation was based on a GPV Mesoscale Model of Japan NWP. It had an 18 hour lead time and updated four times a day. Flood forecasting based on input from forecasted precipitation shows that the accuracy decreases as lead-time increased. It is clear that flood forecasting depends on precipitation forecast accuracy.

Observed precipitation and discharge are used for model updating to determine initial data for flood forecasting. The simplicity of the runoff model gives advantage on water content estimation in soil storage. It is necessary because the runoff model might have basic errors and it needs to have better initial data. Updating calculated discharge with observed discharge approximates the estimation. By estimating more correctly, the model shows to be more reliable.

Keywords: flood forecast, quantitative precipitation forecast, numerical weather prediction, runoff model, updating.
\end{abstract}




\section{Introduction}

This research has two main assets, the runoff model and quantitative precipitation forecasting by product of NWP. The runoff model was proposed by Kato and Mano [1], which is a conceptual-distributed runoff model. This model is simple but proven to be effective as it was tested for a number of flood events in Japan, Tatesawa et al [2].

This paper follows the convention that flow forecasting with lead-times from a few hours to 2 or 3 days is described as short-term forecasts. The forecast is based on a mesoscale NWP that had 18 hours lead time.

The case study is in Shichigasyuku Dam Basin, upstream of the Shiroishi River, Miyagi Prefecture, Japan. It is an operational scale basin with a total area of $237 \mathrm{~km}^{2}$. The model domain is from the dam inlet upward, with a total area of about $180 \mathrm{~km}^{2}$. It has fine spatial and temporal distribution of Precipitation and an adequate discharge monitoring station available with fine temporal resolution. A new era of mesoscale NWP analysis has been starting since March 2002. Since then, only a few flood events have occurred. This paper selects four extreme discharge events from 2002 until 2006. Isolated extreme discharges have occurred twice in 2002, which were on 9th to 12th July and 30th September to 3rd October. Two other are non -isolated events occurred in 2004, which were on the 19 th to 22 nd May and the 8 th to 11 th October.

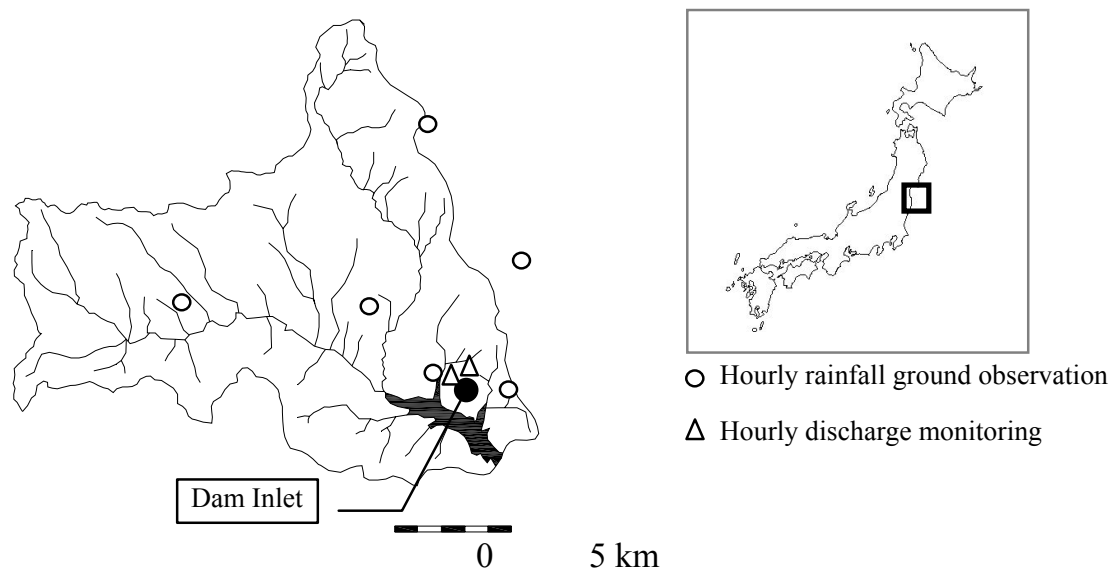

Figure 1: Shichigasyuku Dam Basin.

\section{Numerical weather prediction overview}

Weather Prediction is conducted by the Japanese Meteorological Agency (JMA). The JMA performs three kinds of objective atmospheric analyses for global, regional and mesoscale forecast models. All of them employ a four-dimensional variation (4D-Var) scheme on model coordinates for the analysis of surface pressure, temperature, vector winds and relative humidity. 
The JMA runs the Global Spectral Model (GSM) four times a day (36 hour forecast), Regional Spectral Model (RSM) twice a day (51-hour forecasts) and Mesoscale Model (MSM) eight times a day (15-hour forecasts). The mesoscale model uses fully compressible non-hydrostatic equations within the Japanese domain.

The mesoscale model forecasts 6 times a day but in March 2006 JMA increased horizontal resolution from $10 \mathrm{~km}$ to $5 \mathrm{~km}$ and the number of vertical levels from 40 to 50. JMA also enhanced operation at 03, 09, 15 and 21 UTC as well as previous 00, 06, 12 and 18 UTC and shortened forecast time from 18 hours to 15 hours. See [3] for more detail.

\section{Runoff model}

Distributed models are considered promising because of the new development of various distributed data sets. This paper uses another alternative distributed run off model based on a tank model, which is conceptual with physical explanation.

Topography for the model uses a $50 \mathrm{~m}$ resolution of DEM. Channels are defined into grids. The basin consists of sub basins, each attached to one channel grid. The sub basin represents a drainage area where short period of run of peaks occur and are lumped into channels. Its storage consists of three linear cascade reservoirs that represent soil layers. Water excess and percolation processes in each layer is driven by corresponding saturated hydraulic conductivity and water content.

Input precipitation is GPV observed precipitation called RADAR AMeDAS, it is a Japanese operational radar observation. Interception uses the Crown method, Horton [4], eqn. (1). Infiltration and direct run off are distributed based on saturated hydraulic conductivity $\left(k_{s}\right)$. The $k_{s}$ is approximated using a method from Jabro [5], which requires soil fraction and its properties. The distribution between excess flow and percolation is proportional with water content $(\lambda)$ in lower tank, eqn. (2), see figure. 2. Excess flow is expressed from Darcy Law, eqn. (3).

$$
\begin{gathered}
P=K E T+S \\
\lambda_{i}=\frac{H_{i}}{H_{i \max }} \\
q_{i}=c k_{s i} I \frac{H_{i}}{H_{i \max }}=c k_{s i} I \lambda_{i}
\end{gathered}
$$

where: $P=$ Interception rate

$K=$ Interception rate of stem $(\mathrm{mm} / \mathrm{h})$

$E=$ Evaporation on rain periods $(\mathrm{mm} / \mathrm{h})$

$T=$ Rainfall Duration $(\mathrm{h})$

$S=$ Initial capacity of stem (mm)

Forest area; $K E=0.2 \mathrm{~mm} / \mathrm{hr}$. Cultivated area; $K E=0.1 \mathrm{~mm} / \mathrm{hr}$ (Hattori et al [6], Tsukamoto [7])

$\lambda_{i}=$ Water content in tank 


$$
\begin{aligned}
& q_{i}=\text { Excess saturated flow } \\
& c=\text { deviation constant } \\
& H=\text { water depth on tank } \\
& I=\text { slope of sub basin }
\end{aligned}
$$

Subscript $i$ denotes layer of soil; $H$ follows by subscript max denotes tank depth.

Calibration parameters are $c$ and $S$. Channel routing use kinematics wave approximation $(K W A)$ with manning equation for motion equation and rectangular river section assumption. $K W A$ is solved by first order finite difference.



Figure 2: $\quad$ Runoff model conceptual.

Model performance is indicated by the Nash Sutcliffe Index (NSI), eqn. (4) and volume discharge relative error $(Q R E)$ in percent error eqn. (5) on basin outlet.

$$
\begin{aligned}
& N S I=1-\frac{\sum\left(Q_{o b s}-Q_{c a l}\right)^{2}}{\sum\left(\overline{Q_{o b s}}-Q_{o b s}\right)^{2}} \\
& Q R E=\frac{\left|Q_{c a l}-Q_{o b s}\right|}{\left|Q_{o b s}\right|} \times 100 \%
\end{aligned}
$$

where: $Q_{o b s}=$ observed discharge

$$
Q_{\text {cal }}=\text { calculated discharge (unit volume) }
$$

The result of the run model depicted in table 1, is a comparison between observed and calculated discharge shown in figure 4 . The calibration parameter was $c=10$ for the isolated event and $c=5$ for the non-isolated event. $S=0.05$ gave superior NSI but was poor in discharge relative error. For further investigation $S=0.025$ considered more convenient both for NSI and $Q R E$. 
Table 1: $\quad$ Runoff model result.

\begin{tabular}{|c|c|c|c|c|c|c|}
\hline events & $\begin{array}{c}\text { Obs. } \\
\text { peak } \\
\text { disch. }\end{array}$ & $\begin{array}{l}\text { Calc. } \\
\text { peak } \\
\text { disch. }\end{array}$ & $\begin{array}{l}\text { Obs. } \\
\text { volume } \\
\text { disch. }\end{array}$ & $\begin{array}{l}\text { Calc. } \\
\text { volume } \\
\text { disch. }\end{array}$ & \multirow[t]{2}{*}{$N S I$} & $Q R E$ \\
\hline & $\mathrm{m}^{3} / \mathrm{s}$ & $\mathrm{m}^{3} / \mathrm{s}$ & $\mathrm{m}^{3} / \mathrm{s}$ & $\mathrm{m}^{3} / \mathrm{s}$ & & $\%$ \\
\hline 9 - 12 July 2002 & 603.90 & 517.97 & $1.98 \mathrm{E}+7$ & $1.86 \mathrm{E}+7$ & 0.92 & 16.59 \\
\hline 30 Sept - 3 Oct 2002 & 274.74 & 270.91 & $7.21 \mathrm{E}+6$ & $6.91 \mathrm{E}+6$ & 0.96 & 1.41 \\
\hline 19 - 22 May 2004 & 76.25 & 77.42 & $5.43 \mathrm{E}+6$ & $5.04 \mathrm{E}+6$ & 0.74 & 1.52 \\
\hline $8-11$ Oct 2004 & 94.68 & 118.48 & $1.04 \mathrm{E}+7$ & $8.37 \mathrm{E}+6$ & 0.65 & 20.08 \\
\hline
\end{tabular}

Since numerical calculation was only conducted in channel grid, it took less than 10 minutes to complete the 5 day simulation in the main stream computer $(d t=60 \mathrm{~s}$, matrix size $=140 \times 80)$.

\section{Flood forecast}

In this paper, there are two processes in flood forecasting, which are forecasting and updating. Updating is a process based on past information and forecasting based on the future. In the forecasting process, discharge is calculated based on forecasted precipitation. Based on mesoscale NWP, it will forecast discharge from $t=1$ until $t=18$. Every 6 hours new forecasted precipitation will be issued while observed discharge and observed precipitation is issued hourly.

Before initiating a new discharge forecast, the updating process is conducted to update forecasted discharge with real discharge.

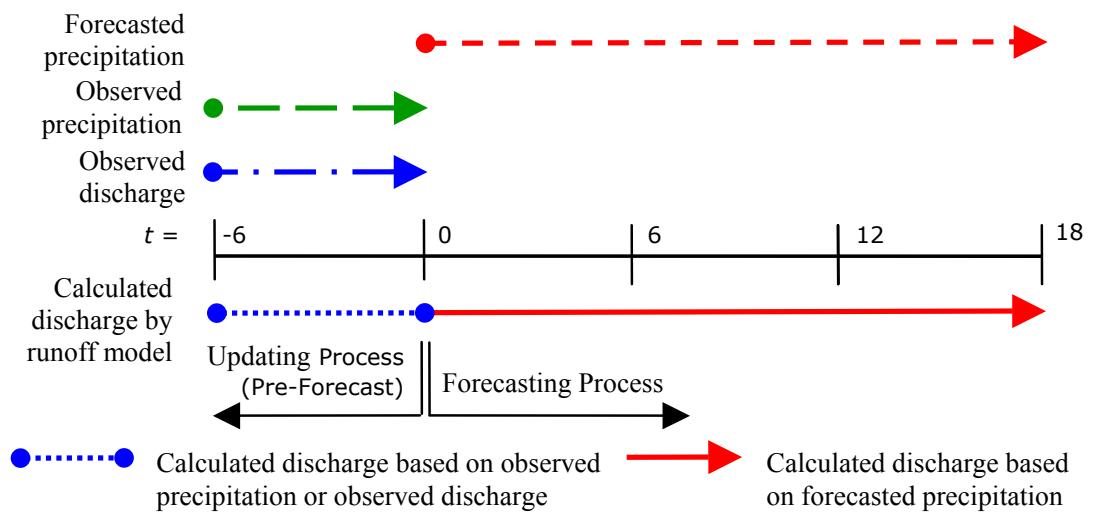

Figure 3: Flood forecast conceptual.

Real time flow forecasts can be improved by continuously comparing forecast results to observations and by changing values of some internal variables or parameters to reduce the differences, Serban and Askew, 1991. The runoff model has only two adjustable parameters and its expected the opportunity to reduce the differences from these parameters will be limited. 
It's unavoidable that the run off model has an error; this error may affect forecast accuracy. Therefore in the updating process, this error should be taken into consideration.

Physical information in an observation point represents processes in its basin; therefore because the basin is small then its outlet (dam inlet) is selected as a representative point. Absolute error can be obtained by reducing $Q_{\text {cal }}$ with $Q_{\text {obs }}$ on the outlet. Absolute error in a certain period represents volume error within the domain. The discharge ratio can be obtained by comparing $Q_{c a l}$ and $Q_{o b s}$ in the outlet, eqn. (7). Forecasted discharge is replaced by real discharge linearly based on the ratio, and distributed it into an entire channel grid.

The main constraint of discharge updating is that the water balance must be maintained. In order to do so after the forecasted discharge is updated with the observed discharge, water depth $(h)$ distribution must be revised by using depth ratio, eqn. (8).

By replacing to the real discharge and new water depth, volume error must be added and distributed into entire domains, i.e. sub-basins. A certain amount of water volume from discharge updating, plus water depth revision, is added to soil storage. By distributing the error correctly then estimation of subsurface water condition can be more accurate. From the Manning Equation, by assuming $h / b$ insignificant then channel discharge $Q$ is

$$
Q=\frac{1}{n} h^{5 / 3} I^{1 / 2} b
$$

If the manning coefficient $n$, slope $I$, and river width $b$ are constant parameter then $Q \approx h^{5 / 3}$. Ratio between $Q_{c a l}$ and $Q_{o b}$ can be approximated with

$$
\begin{gathered}
Q_{\text {ratio }}=\frac{Q_{c a l}}{Q_{o b s}}=\left[\frac{h_{c a l}}{h_{o b s}}\right]^{5 / 3} \\
h_{\text {ratio }}=Q_{\text {ratio }}{ }^{3 / 5}
\end{gathered}
$$

Knowing $Q_{\text {ratio }}$ and $h_{\text {ratio }}$ then we can obtain distribution of revised discharge and water depth, by simple summation, total revised water volume $\left(V_{\text {error }}\right)$ can be determined.

Since sub-basins and Shichigasyuku Basin considered a small basin, fraction of water volume for each sub basin can be approximated from famous rational method, $Q=c i a$, where discharge is linearly proportional with rainfall intensity $i$ and catchment area $a$ by gradient $c$, which is runoff coefficient. Then by assuming uniform runoff coefficient throughout basin.

$$
F q_{j}=\frac{Q_{j}}{Q_{\text {basin }}}=\frac{i_{j} a_{j}}{i_{\text {basin }} a_{\text {basin }}}=F i_{j} F a_{j}
$$

where: $F q_{j}=$ fraction volume discharge of sub-basin

$$
F i_{j}=\text { fraction rain intensity of sub-basin } F i_{j}=\frac{i_{j}}{i_{\text {basin }}}
$$




$$
F a_{j}=\text { fraction area of sub-basin } F a_{j}=\frac{A_{j}}{A_{b a s i n}}
$$

Subscript $j$ denotes each sub-basin; subscript basin denotes total catchment.

The fraction of water volume $F_{q}$ and rain intensity can be obtained instantaneously after $Q_{o b s}$ is issued in the outlet of basin and Radar AMeDAS issued. Then volume of water that will be added to each sub-basin is

$$
V_{j}=V_{\text {error }} F q_{j}
$$

Afterward, distribution of this error for each layer of soil follows the conceptual tank model, which is proportional to $\lambda_{i}$.

\section{Result and discussion}

Since forecasting was issued every 6 hours and has a lead time of 18 hours, then every event such as peak discharge will be forecasted three times. Figure 4 shows discharge and precipitation forecast compared with observed results.

As shown in these figures, the main characteristic of this basin is that discharge responds fast to precipitation input due to the small size of the basin. Interception process seems to be one of main processes that affected early periods of events. The forecasts are able to predict flood events; however there are some errors due to the precipitation forecast inaccuracy.

For comparison, alternatives without observed discharge updating had been proposed. It means discharge updating will only consider precipitation updating, real discharge is calculated based on input observed precipitation. To avoid false alarm, peak discharge forecast is compared at the time $t=$ peak time observed. Table 2 and figure 5 show results and comparisons of selected flood events.

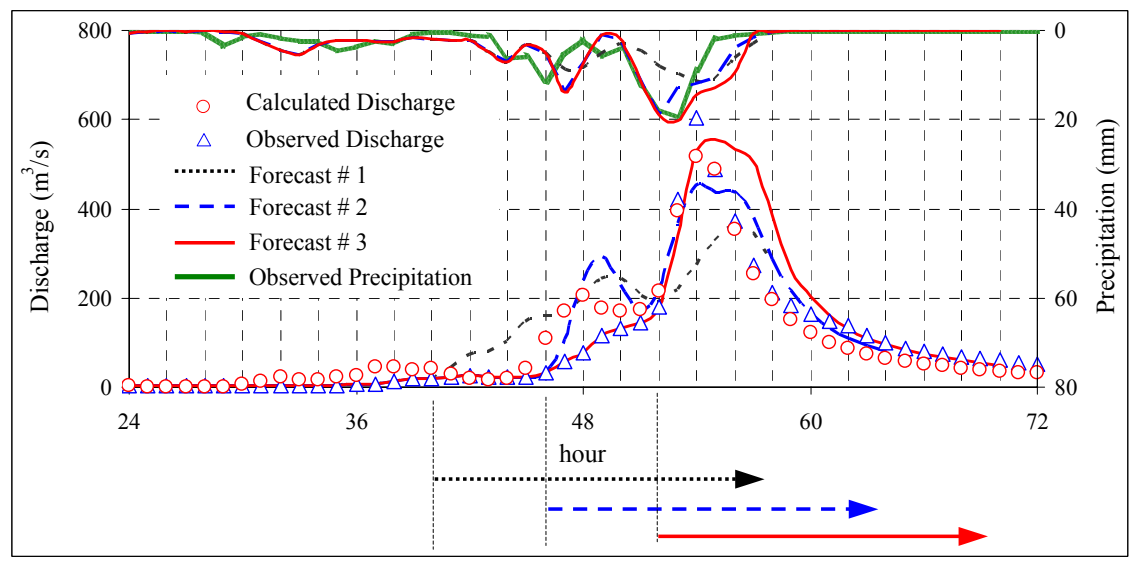

(a)

Figure 4: (a): Flood forecast, event 9 - 12 July 2002; (b): Flood forecast, event 30 September - 3 October 2002; (c): Flood forecast, event 19 - 22 May 2004; (d): Flood forecast, event 8 - 11 October 2004. 


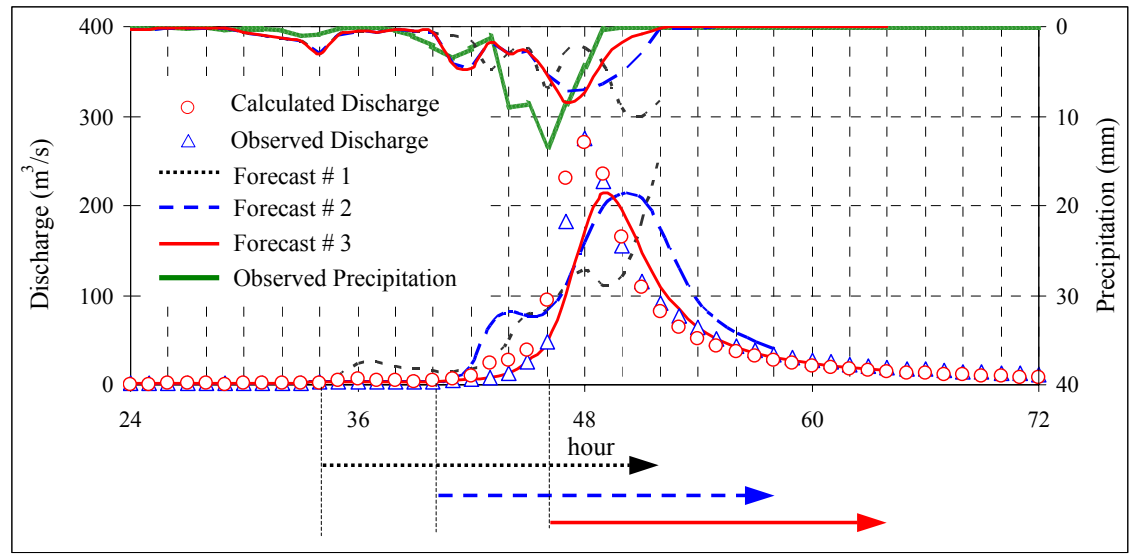

(b)

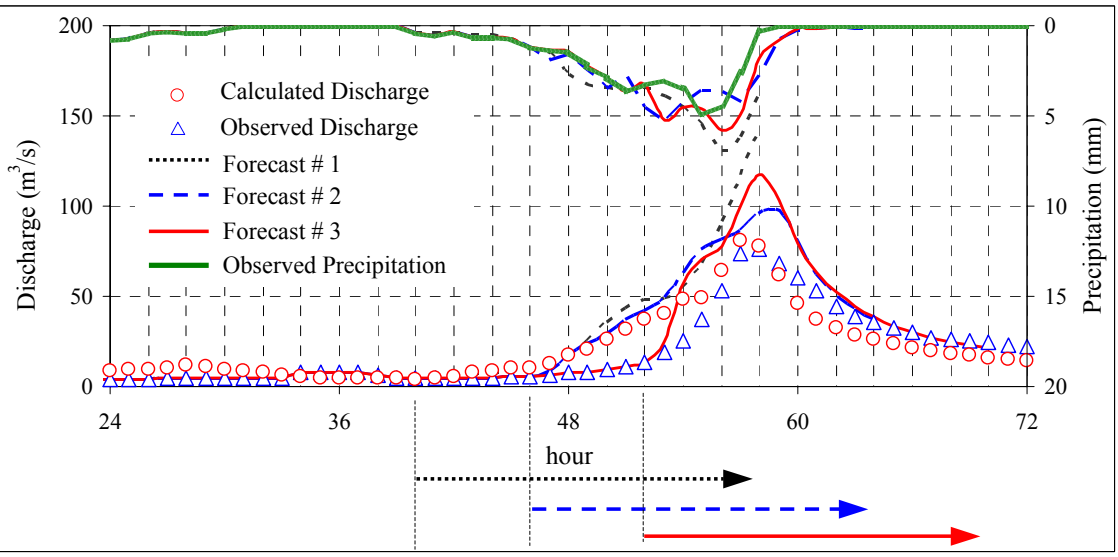

(c)

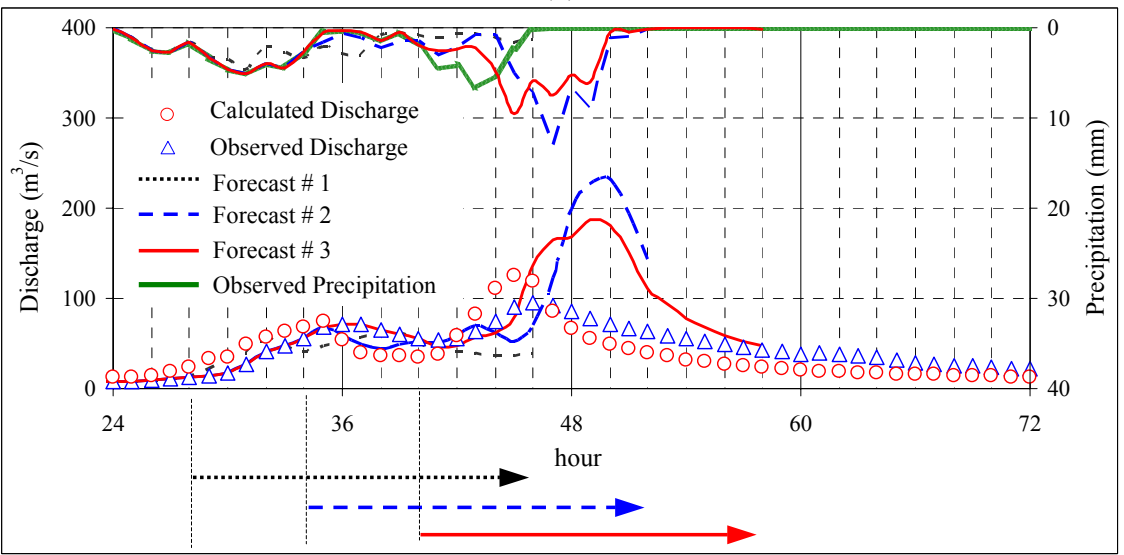

(d)

Figure 4: Continued. 
Table 2: $\quad$ Result without and with observed discharge updating.

\begin{tabular}{|c|c|c|c|c|c|c|c|c|c|}
\hline \multirow[t]{2}{*}{ event } & \multirow{2}{*}{$\begin{array}{l}\text { Lead } \\
\text { Time } \\
\text { hour }\end{array}$} & \multirow{2}{*}{$\begin{array}{l}\text { Obs. } \\
\text { peak } \\
\text { disch. }\end{array}$} & \multicolumn{2}{|c|}{$\begin{array}{c}\text { Calculated peak } \\
\text { discharge } \\
\mathrm{m}^{3} / \mathrm{s}\end{array}$} & \multicolumn{2}{|c|}{$\begin{array}{c}\text { Peak discharge } \\
\text { relative error } \\
\%\end{array}$} & \multicolumn{2}{|c|}{$\begin{array}{c}\text { Volume discharge } \\
\text { relative error } \\
\%\end{array}$} & \multirow{2}{*}{$\begin{array}{c}\begin{array}{c}\text { Volume } \\
\text { prec. } \\
\text { relative } \\
\text { error }\end{array} \\
\% \\
\end{array}$} \\
\hline & & & without & with & without & with & without & with & \\
\hline \multirow{3}{*}{$\begin{array}{c}9-12 \\
\text { July } \\
2002\end{array}$} & 14 & 603.90 & 264.18 & 272.88 & 56.25 & 54.81 & 8.77 & 13.27 & 1.32 \\
\hline & 8 & 603.90 & 451.16 & 453.78 & 25.29 & 24.86 & 20.75 & 11.67 & 11.84 \\
\hline & 2 & 603.90 & 509.23 & 531.07 & 15.68 & 12.06 & 25.59 & 11.86 & 19.48 \\
\hline \multirow{3}{*}{$\begin{array}{l}30-3 \\
\text { Oct } \\
2002\end{array}$} & 14 & 274.74 & 88.28 & 127.82 & 67.87 & 53.48 & 22.10 & 10.12 & 9.99 \\
\hline & 8 & 274.74 & 122.52 & 158.45 & 55.41 & 42.33 & 0.22 & 24.61 & 0.46 \\
\hline & 2 & 274.74 & 171.86 & 170.94 & 37.45 & 37.78 & 22.71 & 7.54 & 15.21 \\
\hline \multirow{3}{*}{$\begin{array}{l}19- \\
22 \\
\text { May } \\
2004\end{array}$} & 18 & 76.25 & 142.13 & 142.13 & 86.40 & 86.40 & 71.54 & 66.85 & 32.73 \\
\hline & 12 & 76.25 & 95.64 & 95.64 & 25.43 & 25.43 & 44.88 & 38.94 & 19.13 \\
\hline & 6 & 76.25 & 117.72 & 117.72 & 54.39 & 54.39 & 37.97 & 22.90 & 21.34 \\
\hline \multirow{3}{*}{$\begin{array}{c}8-11 \\
\text { Oct } \\
2004\end{array}$} & 18 & 94.68 & 39.25 & 39.25 & 58.55 & 58.55 & 18.22 & 17.84 & 25.16 \\
\hline & 12 & 94.68 & 70.09 & 70.09 & 25.97 & 25.97 & 35.78 & 30.60 & 46.32 \\
\hline & 6 & 94.68 & 136.76 & 136.76 & 44.44 & 44.44 & 27.50 & 29.62 & 36.52 \\
\hline
\end{tabular}

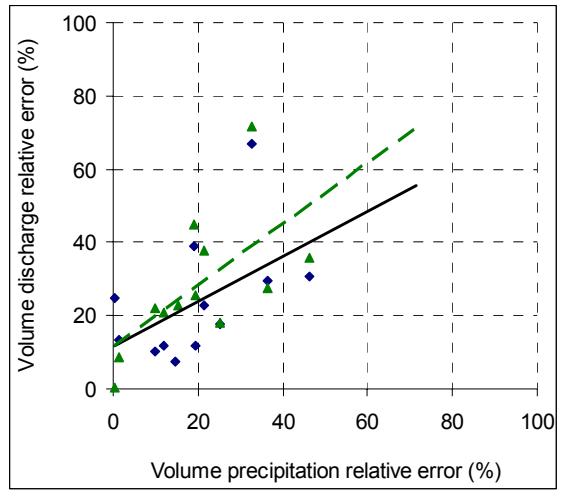

$\Delta \quad$ without $\bullet$ with. $\quad--$ without, linear reg.

(a)

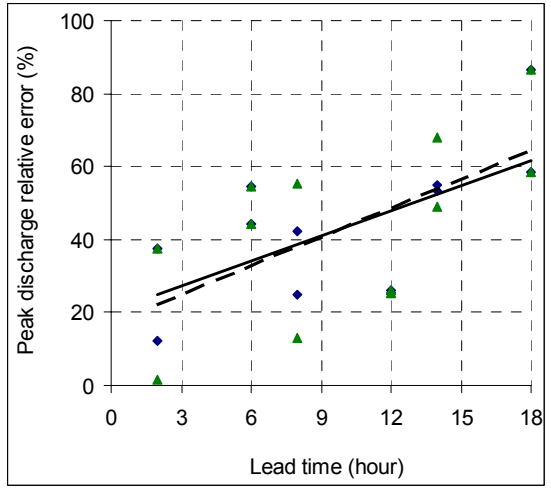

with, linear reg.

(b)

Figure 5: (a): discharge forecast error vs precipitation forecast error; (b): Peak discharge relative error vs lead time.

Due to limited events, the points are quite scattered although they have some tendencies. It is shown that flood forecasting depends on precipitation forecasts. Flood forecasting errors increase as precipitation error increases. Initial discharge error for zero error of precipitation forecast indicates basic error of the runoff model. 
The linear tendency gradient of alternatives, without observed discharge updating, is almost 1; this means that discharge forecast error grows at the same rate as precipitation forecast error. The tendency gradient of alternatives with observed discharge updating appears milder than without one. It indicates the model with observed discharge updating is more reliable, fig. 5(a).

There is almost no improvement in terms of increasing lead-time effort in both alternatives, fig. 5(b). This confirms that the precipitation forecast accuracy is vital for flood forecasting using the runoff model. It's clear that good rainfall forecasting is evident for higher forecast lead times (Moore et al [8]).

\section{Conclusion}

A set of alternative flood forecast models based on run off model and short range Quantitative Forecasted Precipitation has been developed. It is shown that the error of flood forecast is dependant on precipitation forecast. It is also shown that flood forecast accuracy decreases as lead-time is increased.

Updating procedure for runoff forecasting has been proposed. It was applied for small basins and helps the runoff model be more ready to accept forecasted precipitation. However, it does not help increase lead-time performance in case of small basin.

This paper would like to acknowledge Prof. Masaru Kitsuregawa from University of Tokyo for his special contribution providing corresponding GPV data. Special acknowledgment also to Mr. Jiye Zeng from Center for Global Environmental Research for the GPV decoding tool.

\section{References}

[1] Kato, Hiroyashu, Mano, Akira, Flood runoff model on one kilometer mesh for the Upper Chang Jiang River. Proceeding of GIS \& RS in Hydrology, Water Resources, and Environment, 2003.

[2] Tatesawa, Hiroshi, Kardhana, Hadi \& Mano, Akira, Development of versatile flood runoff model using distributed tanks, submitted for Journal of Japan Society of Hydrology \& Water Resources, 2007.

[3] Japan Meteorological Agency. Numerical Weather Prediction of JMA, http://www.jma.go.jp/jma/jma-eng/jma-center/nwp/nwp-top.htm.

[4] Horton, R.H., Rainfall interception, Monthly Weather Review, 47, pp. 602-623, 1919.

[5] Jabro, J.D., Estimation of saturated hydraulic conductivity of soils from particle size distribution and bulk density data, ASAE, 35 (2), pp. $557-$ 560, 1992.

[6] Hattori, Shigeaki., Chikaarashi, Hiroe., \& Takeuchi, Nobuji., Measurement of the rainfall interception and its micrometeorological analysis in Hinoki Stand, Bulletin of the Forestry and Forest Products Research Institute, 318, pp. 79-102, 1982.

[7] Tsukamoto. Conservation of Forest, Water and Soil, Asakura Pubishing Co., Ltd., pp.21-28, 1998. 
[8] Moore, R.J., E. Bell, Victorea A., Jones D.A., Forecasting for flood warning. Geoscience 337, pp. 203-217, 2005.

[9] Wada, Kazunori, Murase, Masahiko, \& Tomizawa, Yosuke, A Study on applicability of precipitation forecasts for river flood management. Civil Engineering Technologies, vol. 47-3, pp. 64-69, 2005.

[10] Vieux, E. B., Cui, Zhengtao, Gaur, Anubhav, Evaluation of a physicsbased distributed hydrologic model for flood forecasting. Journal of Hydrology 298, pp. 155-177, 2004.

[11] Collischonn, Walter, Haas, Reinaldo, Andreolli, Ivanilto, Tucci, C.E.M., Forecasting River Uruguay flow using rainfall forecasts from a regional weather-prediction model. Journal of Hydrology 305, pp. 87-98, 2005. 